The scope of this thiol-catalysed decarbonylation of aldehydes is now under investigation, and details will be submitted for publication in the near future. It is also proposed to search for other instances of dehydrogenation by thiyl radicals, $R-\mathrm{S}^{\cdot}$, since the tentative speculation made by one of us some years $\mathrm{ago}^{5}$ that thiol-containing enzymes may act by promoting homolytic dehydrogenation may now prove to be capable of exemplification with simpler organic molecules.

Dyson Perrins Laboratory,

$$
\text { E. F. P. HARRIS }
$$

$$
\text { W. A. Waters }
$$

Oxford.

Jan. 21.

' See Steacie, E. W. R., "Atomic and Free Radical Reactions" (1946). 2J. Amer. Chem. Soc., 69, 2917 (1947).

${ }^{3} \mathrm{~J}$. Org. Chem., 14, 248 (1949).

- See preceding communication.

'Waters, "The Chemistry of Free Radicals", 257, 283 (1946).

\section{Mechanism of the Reaction between Dichromate and Diphenylcarbazide}

'THE colour reaction between dichromate and diphenylcarbazide in acid medium is the basis of the best method yet devised for the detection and colorimetric estimation of small amounts of chromium. According to Cazeneuve ${ }^{1}$, the intense colour is undoubtedly due to an organo-metallic chromium complex. Attempts were made by Moulin ${ }^{2}$ to isolate the compound but without any success. Thus the mechanism of the reaction has remained unknown. ably owing to the reduction of carbazone to the carbazide in the first case and oxidation of the carbazide to its higher oxidation product carbadiazine, or even further, in the latter case. The spectral curves of three different systems, namely, chromate-carbazide, chromate-carbazone and chromous-carbazone are found to be identical, having an absorption maximum at $540 \mathrm{~m} \mu$.

A quantitative study of the reaction from spectrophotometric measurements was made by the method of $\mathrm{Job}^{3}$. For mixtures of chromate-carbazide and working with equimolecular solutions, the maximum reaction was found to correspond to a ratio of chromate to carbazide of $2: 3$. For the chromate-carbazone reaction this ratio was $1: 3$ and for chromouscarbazone mixtures it was found to be $\mathbf{l}: \mathbf{l}$.

These observations can be explained by the accompanying reactions.

Transport measurements on concentrated solutions of mixtures of chromate and carbazide showed the compound to be of a non-electrolytic type. This is also in conformity with the above formulation of the compound as an inner metallic chromium complex.

That the compound formed contains chromium in the bivalent state is corroborated by magnetochemical methods. Magnetic susceptibility measurements were made with solutions of chromate-carbazide mixtures in which the ratio of chromate to carbazide was $2: 3$ (corresponding to the maximum composition in Job's method, where as a first approximation it can be considered that the complete conversion of chromate to the chromous complex has occurred). The solution was found to be paramagnetic, and calculation gave a susceptibility of $4.5 \mathrm{Bohr}$ mag-

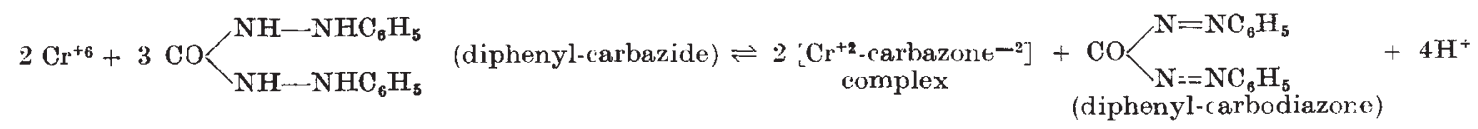

$$
\begin{aligned}
& \mathrm{Cr}^{+6}+3 \mathrm{CO}\left\langle\begin{array} { l } 
{ \mathrm { N } = \mathrm { NC } _ { 6 } \mathrm { H } _ { 5 } } \\
{ \mathrm { NH } - \mathrm { NHC } _ { 6 } \mathrm { H } _ { 5 } }
\end{array} \text { (diphenyl-carbazone) } \rightleftharpoons \left[\mathrm{Cr}^{+2} \text {-carbazone-2] }+2 \text { diphenyl-carbodiazone }+2 \mathrm{H}^{+}\right.\right.
\end{aligned}
$$

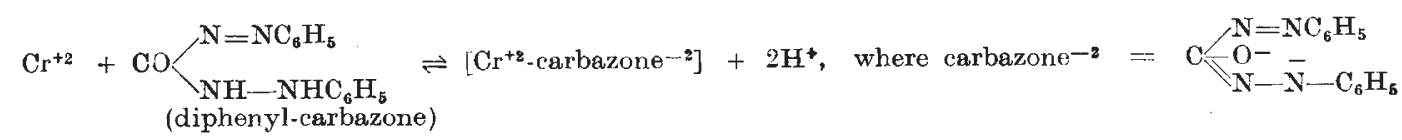

In the present work, attempts have been made to elucidate the mechanism of the reaction from different physico-chemical points of view. It has been noted that, for the reaction to occur, the chromium must be in the hexavalent state. This leads to the conolusion that it must be a redox reaction, and possibly also coupled with complex formation. Chromium in the tervalent state fails to react with either diphenylcarbazide or its oxidation product diphenylcarbazone, but hexavalent chromium reacts with both, producing the same colour reaction. However, chromium in the bivalent state reacts with diphenylcarbazone to produce the same colour reaction, but fails to react with freshly prepared carbazide which is free from carbazone. Excess of chromous ion or excess of dichromate ion destroys the colour, prob- netrons for the moment of chromium, which is undoubtedly due to bivalent chromium.

Details of the mechanism of the reaction and ite kinetics will be published elsewhere.

My thanks are due to Prof. P. 13. Sarkar for his interest and kind encouragement, and to Dr. B. C. Haldar for his helpful suggestions during the progress of the work.

Department of Physical Chemistry, Monisha Bose

University College of Science and Technology, Calcutta 9 . Jan. 21.

${ }^{1}$ Cazeneuve, P., C.R. Acad. Sci., Paris, 131, 346, 347 (1900).

2 Moulin. A., Bull. Soc. Chem., 31, 295 (1904).

${ }_{3}$ Job, P., C.R. Acad. Sci., Paris, 180, 928 (1925). 